\title{
AN ANALYTICAL STUDY OF CARCINOMA OESOPHAGUS AND ITS SURGICAL MANAGEMENT
}

\author{
Yeganathan Rajappan', Ilavarasi Thangavel2, Mahalakshmi Ashokkumar ${ }^{3}$, Manimaran Thangavelu4, Anandan Kanthan ${ }^{5}$
}

${ }^{1}$ Associate Professor, Department of General Surgery, KAPV Government Medical College, Trichy.

${ }^{2}$ Postgraduate Student, Department of General Surgery, KAPV Government Medical College, Trichy.

${ }^{3}$ Assistant Professor, Department of General Surgery, KAPV Government Medical College, Trichy.

${ }^{4}$ Assistant Professor, Department of General Surgery, KAPV Government Medical College, Trichy.

5 Postgraduate Student, Department of General Surgery, KAPV Government Medical College, Trichy.

\section{ABSTRACT}

\section{BACKGROUND}

Carcinoma oesophagus is the $6^{\text {th }}$ most common cancer in the world. Overall, a 5 -year survival rate with treated tumour is 5 to $20 \%$ only. But still most patients with carcinoma oesophagus could not be diagnosed earlier because of late presentation. The aim of this study is to know the regional incidence, common histological types, clinical features and investigations to aid diagnosis, to know the common site and to know operability of carcinoma oesophagus.

\section{MATERIALS AND METHODS}

This study was conducted in Mahatma Gandhi Memorial Government Hospital, Trichy between September 2013 and June 2015. This study included 88 patients of carcinoma oesophagus who were managed through Feeding Jejunostomy with Radiotherapy referral, Transhiatal Oesophagectomy, Thoracoscopic Oesophagectomy and were studied for their regional incidence, clinical features and investigations to aid diagnosis, to know the common site and to know operability of carcinoma oesophagus. The study design was descriptive.

\section{RESULTS}

The incidence of carcinoma oesophagus in Mahatma Gandhi Memorial Govt. Hospital, Trichy has been worked out to be $5.2 \%$. Carcinoma oesophagus is commonly seen in $7^{\text {th }}$ decade of life; $26 \%$ of cases falls in the age group of 61 to 70 years. Youngest patients were of 30 years of age and eldest 90 years. The Male-to-Female ratio is 1.4:1. Carcinoma oesophagus patients with alcohol intake is $27 \%$. Most common complaint according to our study is Dysphagia (98\%) followed by weight loss (62\%). Mostly tumour affects the middle $1 / 3^{\text {rd }}$ of oesophagus $(48 \%)$ followed by lower $1 / 3^{\text {rd }}$ with oesophagogastric junction (31\%). Common histological pattern is squamous cell carcinoma (80\%) in our study; $51 \%$ of patients has ulcerative growth, $43 \%$ have infiltrative growth. Out of 88 patients with carcinoma oesophagus, $54 \%$ of cases underwent Feeding Jejunostomy and referred to Radiotherapy; $46 \%$ of cases have curative surgery done like Transhiatal oesophagectomy (42\%), Thoracoscopic Oesophagectomy (3\%), Total Gastrectomy with oesophagectomy in 1.1\%. Among the patients who underwent curative surgery, 39\% have postoperative complications. Anastomotic leak is the highest post-operative complication with $14 \%$ incidence. Death in post-operative patients was $2 \%$. During the followup period, $12 \%$ of patients were lost. Most of the followup occurred between 7 and 12 months of post-operative period (36\%). Patients with recurrence referred to Radiotherapy.

\section{CONCLUSION}

Carcinoma oesophagus have increased the Male-to-Female ratio. It is most common in low socioeconomic group. Predominant histology is squamous cell carcinoma. Strong association exists between smoking, alcoholism and carcinoma oesophagus. Transhiatal oesophagectomy and thoracoscopic oesophagectomy have significant role in surgical management of carcinoma oesophagus of middle and lower $1 / 3^{\text {rd }}$. About $50 \%$ of patients were inoperable and feeding jejunostomy was done and referred to Radiotherapy.

\section{KEYWORDS}

Carcinoma Oesophagus, Transhiatal Oesophagectomy, Thoracoscopic Oesophagectomy, Feeding Jejunostomy.

HOW TO CITE THIS ARTICLE: Rajappan Y, Thangavel I, Ashokkumar M, et al. An analytical study of carcinoma oesophagus and its surgical management. J. Evolution Med. Dent. Sci. 2017;6(48):3722-3727, DOI: 10.14260/Jemds/2017/803

\section{BACKGROUND}

Carcinoma oesophagus is the $6^{\text {th }}$ most common cancer in the world. Squamous cell carcinoma accounts for most of

Financial or Other, Competing Interest: None.

Submission 26-04-2017, Peer Review 03-06-2017,

Acceptance 09-06-2017, Published 15-06-2017.

Corresponding Author:

Dr. Yeganathan Rajappan,

Associate Professor,

Department of General Surgery,

KAPV Government Medical College and

MGM Government Hospital, Trichy.

E-mail: dryeganathan@gmail.com

DOI: $10.14260 /$ jemds $/ 2017 / 803$ oesophageal cancers.[1],[2] The Male-to-Female ratio is $3: 1$ in SCC and 15:1 in Adenocarcinoma. Smoking and alcohol increase the risk of foregut cancers.[3] Most of the patients could not be diagnosed earlier because of late presentation. ${ }^{[4]}$ Carcinoma oesophagus infiltrate locally, involve adjacent lymph node and metastasise widely by haematogenous spread; 0 - 5 year survival rate[5] with treated tumour is 5 $12 \%$. Carcinoma oesophagus is treated through surgery, chemotherapy and radiotherapy.

Carcinoma oesophagus varies in geographical distribution with highest incidence in Henan province of china. In West adenocarcinoma is increasing with incidence of 5/100000 in USA and 26/1000000 in France. SCC and Adenocarcinoma account for $98 \%$ of carcinoma oesophagus; rest of $2 \%$ 
consists of neuroendocrine tumour, carcinosarcoma, melanoma and sarcoma. Clinical features vary with the stage of carcinoma oesophagus.[6] In early stages the features mimic GERD, heart burns, regurgitation and indigestion. The features of advanced stage are dysphagia, weight loss, choking, coughing, aspiration, hoarseness of voice and jaundice. Among the investigations done, UGI scopy and CT thorax[7] are important. Patients are managed through surgery/radiotherapy/chemotherapy. Among the surgical approaches Transhiatal oesophagectomy and Thoracoscopic oesophagectomy are done usually in our hospital.

\section{MATERIALS AND METHODS \\ Study Place}

Mahatma Gandhi Memorial Hospital and KAPV Govt. Medical College, Trichy.

\section{Duration of Study}

September 2013 to June 2015.

\section{Study Design}

Descriptive Study.

\section{Ethical Committee}

Institutional Ethical Committee, KAPV Govt. Medical College. Approved on April 2015.

\section{Inclusion Criteria}

Any age group. All sex group. Patients with radiologically and biopsy proven carcinoma oesophagus in middle and lower $1 / 3^{\text {rd }}$ of oesophagus without previous treatment for carcinoma oesophagus.

\section{Exclusion Criteria}

Patients with carcinoma oesophagus involving upper $1 / 3^{\text {rd }}$ of oesophagus. Patient with previous treatment for carcinoma oesophagus.

\section{Data Collection and Methods}

Among the 112 patients with carcinoma oesophagus admitted in KAPV Govt. Medical College, Trichy, 88 patients were included for study. Important information from patients was obtained through clinical examination and investigations necessary to aid diagnosis and resectability. All the information was entered in a specially designed proforma. While evaluating the patient's age, sex, geographical factors, socio-economic status, personal habits, symptoms and duration, pre-disposing factors were considered. Per abdominal examination, $\mathrm{RS}$ examination and $\mathrm{P} / \mathrm{R}$ examination was done. Upper GI Endoscopy was done for the patients and biopsy was taken of the location, and type of growth and distance from incisor were noted. Patients with positive endoscopy and biopsy were subjected to USG abdomen to rule out metastasis. CT thorax was done to study the location of tumour, wall thickness, extent of tumour, mediastinal lymph nodes and direct invasion of adjacent structures. CT abdomen was done to find hepatic and adrenal secondaries. Bronchoscopic examination was done to rule out tracheobronchial involvement.
After obtaining necessary information from clinical examination and investigations, curative or palliative treatment was planned. The Curative treatment consists of transhiatal oesophagectomy and thoracoscopic oesophagectomy. Patients who did not fit for curative surgery were subjected to palliative feeding jejunostomy with followup radiotherapy and referred to Oncological Department. Of 88 patients who were diagnosed with carcinoma oesophagus, 41 underwent curative surgery and 47 underwent palliative feeding jejunostomy; 31 patients had transhiatal oesophagectomy, 3 had thoracoscopic oesophagectomy and 1 patient had total gastrectomy and oesophagectomy. Post-operative complications identified promptly and managed accordingly. Most of the patients who underwent surgery were reviewed in OPD. During followup complications like anastomotic leak, recurrence and distant metastasis were examined. Patients who had feeding jejunostomy done was referred to Radiotherapy.

\section{Statistical Analysis}

Descriptive statistics such as frequency and proportions were calculated. To compare the qualitative variables Chi-square test was used, a p-value of $\mathrm{p}$ less than or equal to 0.05 is considered significant.

\section{RESULTS}

The incidence of carcinoma oesophagus by this study in our Institution is $5.2 \%(112 / 2120)$.

Total number of cancer patients in our hospital during this study period were 2120 .

Total number of carcinoma oesophagus were 112.

\begin{tabular}{|c|c|c|}
\hline Age Group (Years) & No. of Cases & Percentage \\
\hline$\leq 30$ & 4 & $5 \%$ \\
\hline $31-40$ & 11 & $13 \%$ \\
\hline $41-50$ & 19 & $22 \%$ \\
\hline $51-60$ & 22 & $25 \%$ \\
\hline $61-70$ & 24 & $26 \%$ \\
\hline $71-80$ & 7 & $8 \%$ \\
\hline$>80$ & 1 & $1 \%$ \\
\hline Total & $\mathbf{8 8}$ & $\mathbf{1 0 0} \%$ \\
\hline \multicolumn{3}{|c|}{ Table 1. Age Incidence } \\
\hline
\end{tabular}

Carcinoma oesophagus is common in $7^{\text {th }}$ decade of life [26\%].

\begin{tabular}{|c|c|c|c|c|}
\hline $\begin{array}{c}\text { Age Group } \\
\text { (Years) }\end{array}$ & Males & Percentage & Females & Percentage \\
\hline$\leq 30$ & 2 & $2 \%$ & 2 & $2 \%$ \\
\hline $31-40$ & 4 & $5 \%$ & 6 & $7 \%$ \\
\hline $41-50$ & 11 & $13 \%$ & 8 & $9 \%$ \\
\hline $51-60$ & 17 & $19 \%$ & 6 & $7 \%$ \\
\hline $61-70$ & 16 & $18 \%$ & 8 & $9 \%$ \\
\hline $71-80$ & 6 & $7 \%$ & 1 & $1 \%$ \\
\hline$>80$ & 0 & 0 & 1 & $1 \%$ \\
\hline Total & $\mathbf{5 6}$ & $\mathbf{6 4 \%}$ & $\mathbf{3 2}$ & $\mathbf{3 6 \%}$ \\
\hline \multicolumn{5}{|c|}{ Table 2. Sex Incidence } \\
\hline
\end{tabular}

\section{Carcinoma Oesophagus is Common among Males [64\%]}

The relation of carcinoma of oesophagus and personal habits has been well established in various studies. 


\begin{tabular}{|c|c|c|}
\hline Habits & No. of Patients & Percentage \\
\hline Tobacco & 8 & $9 \%$ \\
\hline Betel Nut & 17 & $19 \%$ \\
\hline Smoking & 27 & $30 \%$ \\
\hline Alcohol & 24 & $27 \%$ \\
\hline 2 or more habits & 19 & $21 \%$ \\
\hline \multicolumn{3}{|c|}{ Table 3 }
\end{tabular}

According to our study, smoking (30\%) and alcohol $(27 \%)$ users are prone to get carcinoma oesophagus.

\begin{tabular}{|c|c|c|}
\hline Complaints & Number of Cases & Percentage \\
\hline Dysphagia & 86 & $98 \%$ \\
\hline Weight loss & 55 & $62 \%$ \\
\hline Anorexia & 20 & $23 \%$ \\
\hline Vomiting & 15 & $17 \%$ \\
\hline Abdominal pain & 18 & $20 \%$ \\
\hline Chest pain & 3 & $3 \%$ \\
\hline Cough & 4 & $5 \%$ \\
\hline Hoarseness & 0 & $0 \%$ \\
\hline Dyspnoea & 3 & $3 \%$ \\
\hline Melena Table 4. Clinical Features \\
\hline \multicolumn{2}{|c|}{}
\end{tabular}

Among the presenting complaints, the commonest and at many a times the only complaint was dysphagia (98\%). The second most common was the weight loss (62\%).

\begin{tabular}{|c|c|c|}
\hline Location & Number of Cases & Percentage \\
\hline Upper 1/3rd & 24 & $21 \%$ \\
\hline Middle 1/3rd & 52 & $48 \%$ \\
\hline Lower 1/3rd & 21 & $18 \%$ \\
\hline OGJ & 15 & $13 \%$ \\
\hline \multicolumn{2}{|c|}{$\begin{array}{c}\text { Table 5. Distribution of Tumour } \\
\text { according to Site of Tumour }\end{array}$} \\
\hline
\end{tabular}

The commonest site of the carcinoma of oesophagus was the lower $3^{\text {rd }}$ in our Institution, about 52 patients were having middle-third carcinoma (46\%). Lower $3^{\text {rd }}$ along with OGJ contributes to $31 \%$ (36) cases.

Various studies have documented a major shift in the histological pattern of the cancer oesophagus from a traditional squamous cell carcinoma to adenocarcinoma. But, in our study, the commonest histological pattern is still squamous cell carcinoma in our Institution.

\begin{tabular}{|c|c|c|}
\hline Type of Growth & Number of Cases & Percentage \\
\hline Fungating & 3 & $3 \%$ \\
\hline Ulcerative & 45 & $51 \%$ \\
\hline Infiltrative & 38 & $43 \%$ \\
\hline Polypoid & 2 & $2 \%$ \\
\hline \multicolumn{3}{|c|}{ Table 6. OGD Scopy Finding } \\
\hline
\end{tabular}

Most of the patients (51\%) were found to have ulcerative growth. Infiltrating type of growth (43\%) were the second most common type of growth.

\begin{tabular}{|c|c|c|}
\hline Type & Number of Cases & Percentage \\
\hline Squamous & 70 & $80 \%$ \\
\hline Adeno & 18 & $20 \%$ \\
\hline Total & $\mathbf{8 8}$ & $\mathbf{1 0 0} \%$ \\
\hline \multicolumn{3}{|c|}{ Table 7. Histological Varieties } \\
\hline
\end{tabular}

\begin{tabular}{|c|c|c|}
\hline Surgery & No. of Cases & $\mathbf{\%}$ \\
\hline Transhiatal Oesophagectomy & 37 & $\mathbf{4 2 \%}$ \\
\hline Thoracoscopic Oesophagectomy & 3 & $\mathbf{3 \%}$ \\
\hline Feeding Jejunostomy & 47 & $\mathbf{5 4 \%}$ \\
\hline $\begin{array}{c}\text { Total Gastrectomy with } \\
\text { Oesophagectomy }\end{array}$ & 1 & $\mathbf{1 \%}$ \\
\hline Table 8. Curative and Palliative Surgery \\
\hline
\end{tabular}

Patients were selected for curative surgery according to their general condition, scopy findings, extent of disease, histological grade of lesion without any metastases and complications. ${ }^{[8]}$ Patients selected for curative surgery were planned for either transhiatal oesophagectomy ${ }^{[9]}$ or thoracoscopic oesophagectomy.[10]

Patients in whom there is no curative resection possibility underwent feeding jejunostomy and followup Radiotherapy.[11] Out of those 88 patients, 47 patients underwent feeding jejunostomy followed by radiotherapy. These 47 patients had one of these following exclusion criteria.

\begin{tabular}{|c|c|c|}
\hline Factors & Number of Cases & Percentage \\
\hline$>80$ years & 2 & $2 \%$ \\
\hline Co-morbid illnesses & 4 & $5 \%$ \\
\hline $\begin{array}{l}\text { Poor general } \\
\text { condition }\end{array}$ & 8 & $9 \%$ \\
\hline Extensive growth & 24 & $27 \%$ \\
\hline Metastases & 6 & $7 \%$ \\
\hline $\begin{array}{l}\text { Not willing for } \\
\text { major surgery }\end{array}$ & 3 & $3 \%$ \\
\hline Total & 47 & $53 \%$ \\
\hline
\end{tabular}

All these patients underwent palliative feeding jejunostomy and referred to Radiotherapy Unit for further management.

Patients (41) who had curative surgery like transhiatal oesophagectomy and thoracoscopic oesophagectomy had following post-operative complications.

\begin{tabular}{|c|c|c|}
\hline Complications & Number of Cases & Percentage \\
\hline Wound infection & 3 & $7 \%$ \\
\hline Anastomotic leak & 6 & $14 \%$ \\
\hline Stricture & 1 & $2 \%$ \\
\hline Wound dehiscence & 4 & $9 \%$ \\
\hline Pneumonitis & 2 & $5 \%$ \\
\hline Haemothorax & 0 & $0 \%$ \\
\hline Death & 1 & $2 \%$ \\
\hline Total & 17 & $39 \%$ \\
\hline \multicolumn{3}{|c|}{ Table 10 } \\
\hline
\end{tabular}

3 patients who had wound infections and 4 patients who had wound dehiscence were managed conservatively and settled in followup; of those patients 6 patients had anastomotic leak in post-operative ward itself, those were managed as inpatients conservatively. ${ }^{[12]}$

Leak stopped and discharged after that; 2 patients developed pneumonitis and treated medically; 1 died in postoperative period itself.

According to above observations, immediate postoperative mortality was $2 \%$. 
Followup periods of (41) patients were variable. During followup visits patients were subjected to investigations to find out any recurrence and any evidence of metastases. Those patients were referred for radiotherapy department in our hospital for further management.

Since the study period was 1 year 10 months, survival rate could not be calculated with these above data.

\section{Statistical Analysis}

\begin{tabular}{|c|c|c|c|}
\hline & SCC & Adeno. CA & $\begin{array}{c}\text { Marginal } \\
\text { Row Total }\end{array}$ \\
\hline Smokers & $\begin{array}{c}16(21.48) \\
(1.4)\end{array}$ & $\begin{array}{c}11(5.52) \\
(5.43)\end{array}$ & $\mathbf{2 7}$ \\
\hline Non-Smokers & $\begin{array}{c}54(48.52) \\
(0.62)\end{array}$ & $\begin{array}{c}7(12.48) \\
(2.4)\end{array}$ & $\mathbf{6 1}$ \\
\hline Total & $\mathbf{7 0}$ & $\mathbf{1 8}$ & $\mathbf{8 8}$ \\
\hline
\end{tabular}

Chi-square statistics is 9.8517

"p" value is 0.001697 .

This result is significant at $\mathrm{p}<0.05$

\begin{tabular}{|c|c|c|c|}
\hline & SCC & Adeno & Total \\
\hline Alcohol & 16 & 8 & $\mathbf{2 4}$ \\
\hline $\begin{array}{c}\text { Non-Alcohol } \\
\text { Users }\end{array}$ & 54 & 10 & $\mathbf{6 4}$ \\
\hline & $\mathbf{7 0}$ & $\mathbf{1 8}$ & $\mathbf{8 8}$ \\
\hline
\end{tabular}

Chi-square statistics is 3.364 .

" $\mathrm{p}$ " value is 0.0495 , significant at $<0.05$

\begin{tabular}{|c|c|c|c|}
\hline $\begin{array}{c}\text { Site of } \\
\text { Carcinoma }\end{array}$ & $\begin{array}{c}\text { Curative } \\
\text { Surgery }\end{array}$ & FJ & Total \\
\hline Middle $1 / 3$ & 28 & 24 & 52 \\
\hline Lower $1 / 3$ & 13 & 23 & 36 \\
\hline Total & 41 & 47 & 88 \\
\hline
\end{tabular}

The Chi-square statistic is 2.6889. The "p" value is $0.10>$ 0.05 .

It is not significant.

\begin{tabular}{|c|c|c|c|}
\hline & SCC & Adeno. CA & Total \\
\hline $\begin{array}{c}\text { Curative } \\
\text { Surgery }\end{array}$ & 34 & 7 & 41 \\
\hline FJ & 36 & 11 & 47 \\
\hline & $\mathbf{7 0}$ & $\mathbf{1 8}$ & $\mathbf{8 8}$ \\
\hline
\end{tabular}

Chi-square statistic is 0.5394 .

"p" value of $0.46>0.05$, not significant.

\section{DISCUSSION}

\section{Epidemiology, Sex and Age Incidence}

The epidemiological characteristics of oesophageal carcinoma are unusual, since the incidence in different geographic areas is extremely variable with the greatest differences recorded for all tumours. The incidence of oesophageal carcinoma varies from $8.1 \%$ recorded at Chennai registry to $4.6 \%$ in Delhi. The incidence as per the surveillance made by the National Cancer Registry Project (NRCP) quotes an incidence of $8.6 \%$ at Bangalore and $6.8 \%$ at Mumbai. The incidence of carcinoma oesophagus in our Institution is $5.2 \%$.
As per the study, the rise in oesophageal cancer commences in the thirties and peaks in the $6^{\text {th }}$ decade. Studies conducted both in India and abroad show peak incidence in the $7^{\text {th }}$ and $8^{\text {th }}$ decades.

\section{Aetiology and Risk Factors}

All the patients in our study, who presented with oesophageal carcinoma were of the lower socioeconomic group. Day and Munoz 1982 and Scottenfeld 1984, and several other series have shown an association between oesophageal cancers and low socioeconomic status.

Low levels of retinol, riboflavin, ascorbic acid and alpha tocopherol are prevalent in population of Linxian, China where oesophageal cancer is epidemic. In Japan, poor food variety has been identified as a risk factor and combination of fruits and vegetables and sand fresh meat appear to be risk reducing factors.

De Carli et al 1989 has stated that low intake of fruits, particularly citrus fruits has much of vitamin $\mathrm{C}$ associated with increased risk deficiency of Zinc and Molybdenum, also cited as possible aetiological factors.

Francheschi et al 1990 discovered that deficiencies are believed to make one more susceptible to the carcinogenic effects of exogenous factors.

From the data given in our study, there is strong association between the use of tobacco in both of its forms of usage (Chewing and Smoking).

The most important risk factors for cancer oesophagus in developed countries are cigarette smoking (IARC 1986) alcohol consumption (IARC 1988). The association between cigarette smoking and alcohol consumption and oesophageal cancer is difficult to separate, largely because of the correlation in the two exposures and their mutual association with the risk of cancer oesophagus.

The risk of oesophageal cancer has shown to be increased among non-tobacco smokers who consume alcohol and nondrinkers of alcohol who smoke tobacco, (La Vecchia and Negri 1989).

The role of alcohol consumption was not clearly demonstrated in the French Department of Ille-et-Vilaine, where the risk rose steadily with the amount of alcohol consumed (Tuyns et al 1977).

The risks associated with tobacco use appears to increase with the number of cigarettes smoked per day, duration of smoking and tar content (Tuyns et al 1979; Rossi et al 1982; Yu et al 1988).

The synergistic effect for the combined habit of alcohol drinking and tobacco smoking or chewing has also been reported.

\section{Morphological Type and Location}

The prominent histological type noted in our hospital is squamous cell carcinoma (80\%).

In Europe and America, adenocarcinoma is more prevalent.

Stiger et al 1987, stated that primary adenocarcinoma represent $3-8 \%$ of the oesophageal cancer. Observations made in our study also show a rise in the incidence of adenocarcinoma $(20 \%)$. 
Oesophageal cancer is usually located in the middle third in about 50\%, and in upper and lower third oesophagus contributes only less (Giuli and Gignoux 1980).

In our study, we found same result as that of Giuli and Gignoux 1980 the Middle third carcinoma is contributing about $48 \%$. Lower third and upto OGJ were about $31 \%$. Carcinoma in Upper third was 21\%.

\section{Surgical Approach}

Transhiatal oesophagectomy without thoracotomy (Orringer et al 1993) has been performed by an increasing number of authors in recent years. It is performed by isolating the mediastinal oesophagus through a cervicotomy and laparotomy (Orringer et al 1984, 1987). We at KAPV Govt. Medical College and MGM GH, Trichy, have adopted this technique in the selected patients for so many years.

In the recent time, we adopted Thoracoscopic oesophagectomy[13] and the operative morbidity and mortality is less with this technique. All 3 cases who had undergone thoracoscopic oesophagectomy had less postoperative morbidity and mortality.

Akiyama et al 1978 stated that stomach is the viscus of choice to replace the oesophagus resected for cancer. It is isolated, tubulised before transposition. According to this statement, stomach tubulisation allows removal of the lymph nodes located in the gastric vessels, a possible metastasis station, improves the gastric vascularisation and avoids mediastinal encumbrance, which is possible when the whole stomach is transposed.

Interpositioning of colonic segment and the transposition of a Roux-en-Y loop of jejunum was done on one case of lower oesophageal cancer.

In our Institution, oesophagogastric anastomosis was done by hand-sewn technique.

Wong et al 1987, identified that the main post-operative complication is the anastomotic leakage. The anastomotic leakage rate in our cases is well within our acceptable range. It was about $14 \%$.

\section{Result of Surgical Resection}

Contrasting data regarding the respectability rates and the long-term survival rates are reported in literature, that is because of varying criterias for the selection of patients for different types of treatment and biological behaviour of the disease.

Observations in our study, the mortality rate was about $2.0 \%$.

\begin{tabular}{|c|c|}
\hline Studies & Percentage \\
\hline Katariya et al & $6.7 \%$ \\
\hline Moon et al & $7.3 \%$ \\
\hline Michigan University & $7.2 \%$ \\
\hline Goldminc et al & $6.4 \%$ \\
\hline Bolton et al & $5.9 \%$ \\
\hline Schakelfordt et al & $5.7 \%$ \\
\hline Orringer et al & $4.0 \%$ \\
\hline Our Study & $2.0 \%$ \\
\hline \multicolumn{2}{|c|}{ Table 11. Post-Operative Mortality } \\
\hline
\end{tabular}

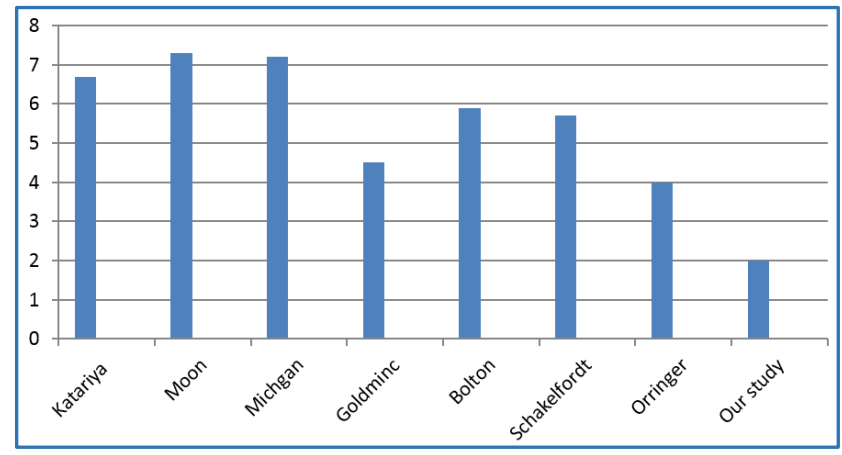

Figure 1

Anastomotic leak observed in our study was about $14 \%$. All were managed conservatively.

\begin{tabular}{|c|c|}
\hline Studies & Anastomotic Leak \\
\hline Katariya et al & $15 \%$ \\
\hline Goldminc et al & $14 \%$ \\
\hline Michigan University & $12.0 \%$ \\
\hline Schekelfordt et al & $13.5 \%$ \\
\hline Orringer et al & $7.9 \%$ \\
\hline Our Study & $14 \%$ \\
\hline \multicolumn{2}{|c|}{ Table 12 } \\
\hline
\end{tabular}

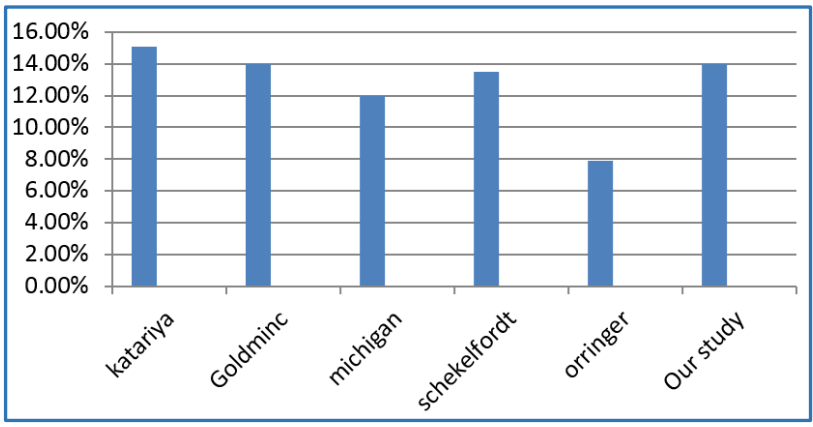

Figure 2

One year survival rate according to our study was $25 \%$.

Since the study period was very less, we were unable to calculate the 5-year survival rate.

\section{CONCLUSION}

- Carcinoma oesophagus is one among the cancers that have increased male: female ratio.

- More commonly occurring in low socioeconomic groups.

- The predominant histology is squamous cell variety.

- There is significant rise of adenocarcinoma.

- A strong association coexists between carcinoma oesophagus with smoking and alcoholism.

- Transhiatal oesophagectomy and thoracoscopic oesophagectomy scores significant role in surgical management of lower $1 / 3$ and middle $1 / 3$ carcinomas.

- Around $50 \%$ of the patients when diagnosed were in inoperable stage.

- Inoperability is due to biological nature of the disease, in which feeding jejunostomy and followup RT is the treatment option.

- Significant 1-year survival rate can be achieved by transhiatal as well as thoracoscopic oesophagectomy. 


\section{ACKNOWLEDGEMENT}

I thank the Dean of KAPV Govt. Medical College, Trichy, Prof. Dr. M. K. Muralitharan MS, MCH for permitting me to conduct this study in the Department of General Surgery of KAPV Govt. Medical College, Trichy. I thank Prof. Dr. Thulasi MS, DGO, Head of Department of General Surgery and my Unit Chief Associate Prof. Dr. R. Yeganathan, MS, DA for helping and guiding me during this study. I am greatly thankful to my Assistant Professors, Dr. Mahalakshmi Ashokkumar MS, DGO and Dr. T. Manimaran MS, who have given their valuable time in guiding me in many aspects of this study and in honing my surgical skills. I also thank Professor of Surgical Gastroenterology, Dr. R. R. Kannan MS, MCH, for helping me in this study. My gratitude to the Professor and Assistant Professors of all other Units. I thank my fellow postgraduates who helped me in conducting this study. I am thankful to all my patients for successful completion of this study.

\section{REFERENCES}

[1] Zhang Y. Epidemiology of esophageal cancer. World J Gastroenterol 2013;19(34):5598-606.

[2] Napier KJ, Scheerer M, Misra S. Esophageal cancer: a review of epidemiology, pathogenesis, staging work up and treatment modalities. World Journal of Gastrointest Oncology 2014;6(5):112-20.

[3] Polenak AP. Secular trend in U.S. black-white disparities in selected alcohol related cancer incidence rates. Alcohol Alcohol 2007;42(2):125-30.

[4] Enzinger PC, Mayer RJ. Oesophageal cancer. N Engl J Med 2003;349(23):2241-52.
[5] Polendak AP. Trend in survival of both histological types of esophageal cancer in US surveillance, epidemiology and end result areas. Int J Cancer 2003;105(1):98-100.

[6] Pennathur A, Gibson MK, Jobe BA, et al. Oesophageal carcinoma. Lancet 2013;381(9864):400-12.

[7] Kumbasar B. Carcinoma of esophagus: radiologic diagnosis and staging. Euro J Radiol 2002;42(3):17080.

[8] Safranek PM, Cubitt J, Booth MI, et al. Review of open and minimal access approaches to esophagectomy for cancer. Br J Surgery 2010;97(12):1845-53.

[9] Orringer MB, Sloan H. Esophagectomy without thoracotomy. J Thoracic Cardiovasc Surg 1978;76(5):643-54.

[10] Yammamato S, Kawahara K, MacKawa T, et al. Minimally invasive esophagectomy for stage 1 and stage 2 esophageal cancer. Ann Thoracic Surg 2005;80(6):2070-5.

[11] Jabbour SK, Thomas CR. Radiation therapy in postoperative management of esophageal cancer. J Gastrointestinal Oncology 2010;1(2):102-111.

[12] Orringer MB, Marshall B, Lannettoni MD. Eliminating the cervical esophagogastric anastamotic leak with a side-to-side stapled anastomosis. J Thoracic Cardiovasc Surg 2000;119(2):277-88.

[13] Luketich JD, Alvelo-Rivera M, Bueneventura PO, et al. Minimally invasive esophagectomy: outcome with 222 patients. Ann Surg 2003;238(4):486-95. 